Int. J. Dev. Biol. 51: 679-687 (2007)

doi: $10.1387 / \mathrm{ijdb} .072364 \mathrm{de}$

\title{
Development of Johnston's organ in Drosophila
}

\author{
DANIEL F. EBERL*,1 and GRACE BOEKHOFF-FALK ${ }^{2}$ \\ ${ }^{1}$ Department of Biology, University of lowa, lowa City, IA and ${ }^{2}$ Department of Anatomy, University of Wisconsin, Madison, WI, USA
}

\begin{abstract}
Hearing is a specialized mechanosensory modality that is refined during evolution to meet the particular requirements of different organisms. In the fruitfly, Drosophila, hearing is mediated by Johnston's organ, a large chordotonal organ in the antenna that is exquisitely sensitive to the near-field acoustic signal of courtship songs generated by male wing vibration. We summarize recent progress in understanding the molecular genetic determinants of Johnston's organ development and discuss surprising differences from other chordotonal organs that likely facilitate hearing. We outline novel discoveries of active processes that generate motion of the antenna for acute sensitivity to the stimulus. Finally, we discuss further research directions that would probe remaining questions in understanding Johnston's organ development, function and evolution.
\end{abstract}

KEY WORDS: audition, hearing, scolopidia, chordotonal organ, active mechanics

\section{Introduction}

Practically the entire progress in genetic and molecular elucidation of hearing mechanisms in the fruitfly, Drosophila melanogasterhas occurred in the last decade. The Johnston's organ (JO), located in the fly's antenna, formally has been confirmed as the major auditory organ and mutations in many genes required for hearing have been identified using a variety of approaches. These include mutagenesis screens, gene expression patterns and other candidate gene approaches including homology to known human hereditary hearing loss genes-almost all of which have been identified over the same time period. Thus, Drosophila hearing research has metamorphosed into an exciting research field that ties together intricate physiological and mechanical mechanisms with complex developmental biology. Several reviews have summarized aspects of this progress (Eberl, 1999, Caldwell and Eberl, 2002, Jarman, 2002, Robert and Göpfert, 2002, Todi et al., 2004, Boekhoff-Falk, 2005). In this paper, we first focus on advances that reinforce the emerging conclusion that the $\mathrm{JO}$ is much more than a mere recapitulation of the canonical larval chordotonal sense organ type. Instead, the Drosophila JO represents an evolution to a highly specialized organ for hearing, clearly chordotonal in nature, but with some features as different from ancestral proprioceptors as the butterfly is from the caterpillar. Second, we highlight some important questions raised by these considerations, the answers to which will represent significant advances in the decade(s) to come.

\section{Drosophila chordotonal organs and their functions}

Selection pressures on the functions of specific sense organs have long-term effects on whether those functions will be maintained and further perfected, whether functions will be attenuated, even lost, or whether novel functions will arise. The diverse chordotonal organs of Drosophila almost certainly derive from a common ancestral mechanosensor whose developmental genetic program has been modified in multiple ways to generate chordotonal organs of distinct sizes and functions.

In the larva, the eight scolopidia (five of them shown in Figure 1) per abdominal hemisegment provide touch sensitivity and during locomotion they provide sensory feedback to the locomotor circuit (Kernan et al., 1994, Caldwell et al., 2003). In the adult, the femoral chordotonal organs ( $\mathrm{fCHO}$ ) comprise three clusters totaling about 74 scolopidia (Figure 2) per leg (Shanbhag et al., 1992) and provide proprioceptive feedback. In the absence of this feedback, chordotonal mutant flies are somewhat ataxic (Eberl et al., 2000). The $\mathrm{fCHO}$ has been shown to participate in a resistance reflex (Reddy et al., 1997). The wing and haltere chordotonal organs (Miller, 1950) provide proprioceptive feedback during flight. This feedback is essential, as strong chordotonal mutants are flightless (Eberl, unpublished). Wing chordotonal organs also provide feedback during singing. Males generate courtship songs by unilateral wing extension and vibration and the courtship songs

Abbreviations used in this paper: fCHO, femoral chordotonal organs; JO, Johnston's organ.

*Address correspondence to: Daniel F. Eberl. Department of Biology, University of lowa, lowa City, IA 52242-1324, USA. Fax: +1-319-335-1069.
e-mail: daniel-eberl@uiowa.edu

0214-6282/2007/\$30.00

(c) UBC Press

Printed in Spain

www.intjdevbiol.com 

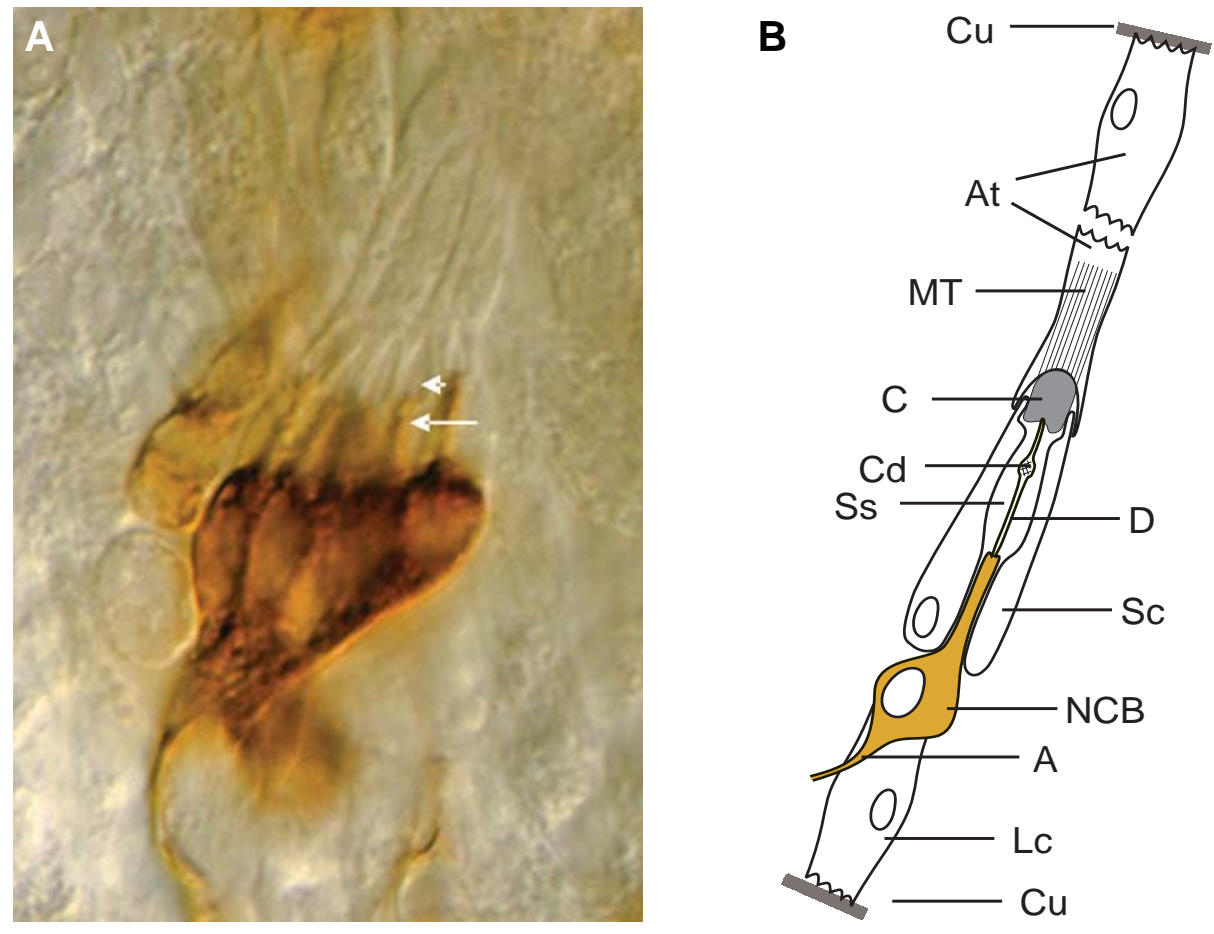

Fig. 1. Drosophila embyronic chordotonal organs. (A) The pentascolopidial organ (Ich5) in the embryonic lateral body wall stained with monoclonal antibody 22C10, visualized with DAB and viewed with Nomarski optics. This antibody stains the Futsch protein in the membranes of all neurons. In chordotonal neurons it stains the inner dendritic segment (arrow) but not the cilium (arrowhead). The scolopale space is visible in relief surrounding the cilium. (B) Schematic of embryonic chordotonal organ structure. Abbreviations: $A$, axon; At, attachment cell; $C$, dendritic cap; Cd, ciliary dilation; $C u$, cuticle; $D$, dendritic outer segment; Lc, ligament cell; MT, microtubules; NCB, nerve cell body; Sc, scolopale cell; SS, scolopale space.

and wing positioning of chordotonal mutant males are aberrant (Tauber and Eberl, 2001), likely because direct feedback of the wing chordotonal organ onto the singing motor circuit is lacking. Chordotonal organs of the bilateral Wheeler's organs, each with about 20 scolopidia in the first two abdominal sternites (Miller, 1950, Bodmer et al., 1987, Jarman et al., 1993, Elliott et al., 2005) have not been functionally characterized, but are likely to have a sensory function either in abdominal position or abdominal distension. A prothoracic chordotonal organ with about 20 scolopidia (Hertweck, 1931, Power, 1948, Miller, 1950, Jarman et al., 1993, Phillis et al., 1996), connecting the prothoracic sternites to the sternal apodeme, has not been tested functionally in Drosophila, but in the blowfly, Calliphora, has been shown to respond to changes in head position (Milde et al., 1987, Strausfeld et al., 1987).

Interestingly, a homolog of this chordotonal organ appears to have evolved into a tympanal auditory organ in two independent dipteran lineages: tachinid and sarcophagid flies (Lakes-Harlan et al., 1999). These authors also show that in a related nonhearing sarcophagid, the prosternal chordotonal organ is present and responds physiologically to direct mechanical stimulation of the prosternal cuticle but not to airborne sound presented in the same stimulus patterns. Thus, cuticular thinning appears to be a major prerequisite for efficient acousto-mechanical transformation in tympanal organs; nevertheless, molecular and cellular modifications in the sensory organs also are likely to be necessary.

$\mathrm{JO}$ is the largest chordotonal organ in the fly, with about 227 scolopidia (Kamikouchi et al., 2006) in the second antennal segment (a2) (Figure 3). Electrophysiological analysis was used to demonstrate that $\mathrm{JO}$ mediates hearing (Eberl et al., 2000). In insects such as mosquitoes, auditory function can be even more highly elaborated, as evidenced in several ways. First, numbers of scolopidia are very high-over 7000 in male Aedes aegypti-resulting in auditory organs as prominent as the eyes (Boo and Richards, 1975a, Boo and Richards, 1975b). Secondly, the morphological diversity appears greater, with as many as four clear morphological types (Boo and Richards, 1975a, Boo and Richards, 1975b). Thirdly, flagellar size, shape and branching arrangement are more extensive in mosquitoes. Fourthly and perhaps complementing this, the auditory physiological mechanisms in the mosquito antenna include more complex dynamics, including frequency matching during courtship and more complex non-linearities in the antennal mechanics (Göpfert and Robert, 2001a, Gibson and Russell, 2006, Jackson and Robert, 2006).

While hearing is the best-characterized function of $\mathrm{JO}$ in Drosophila, this organ also appears to be important for gravitactic behavior (Armstrong et al., 2006). A third function of JO, by homology to other Diptera (Burkhardt, 1960, Gronenberg and Strausfeld, 1990), likely involves detection of wind currents, either during flight or during walking. Indeed, Drosophila shows a strong anemotactic response in flight (Budick and Dickinson, 2006) and possibly when walking (Johnston, 1982), though in neither of these studies was the identity of the sense organ addressed. In other insects that use the antenna as a tactile organ, such as the green stink bug Nezara viridula (Jeram and Pabst, 1996), JO contributes to touch sensitivity as well. These different functions and any additional functions not yet discovered, are likely to impose certain conflicting constraints on the genetic architecture by which chordotonal organs develop and by which they diversify.

\section{Comparative analysis of Drosophila chordotonal or- gan morphology and development}

In this section we will discuss morphological and developmental similarities and differences between $\mathrm{JO}$ and other chordotonal organs in Drosophila. In addition to JO (Figure 3), two other wellstudied DrosophilaCHOs are the pentascolopidial organ (Ich5) of the larval abdominal body wall (Figure 1) and the femoral chordotonal organ ( $\mathrm{fCHO}$ ) of the adult leg (Figure 2). Our understanding of most developmental events in the formation of $\mathrm{JO}$ has 
been inferred by extrapolation from detailed studies in these other two organs. However, growing evidence of differences in developmental genetic mechanisms among Drosophila CHOs makes direct analysis of $\mathrm{JO}$ imperative. These differences also underscore the uniqueness of $\mathrm{JO}$ and provide evidence of genomic plasticity in ontogeny and evolution.

$\mathrm{JO}$ contains $477 \pm 24$ neurons in an estimated 227 scolopidial units (Kamikouchi et al., 2006). This estimate is based on the observation that $10-15 \%$ of $\mathrm{JO}$ scolopidia include three neurons (Todi et al., 2004), the remainder two neurons. All CHOs in which it has been investigated utilize the basic helix-loop-helix (bHLH) proneural transcription factor Atonal (Ato) for specification of their sense organ precursors (SOPs) (Jarman et al., 1993, Jarman et al., 1995). In the antennal imaginal disc at mid-third instar, there is a complete ring of ato-expressing cells in presumptive a2. This ring resolves by late third instar into stronger expression in the three clusters of presumptive SOPs that give rise to JO (Jarman et al., 1993). JO neurons become recognizable by staining with the pan-neural antibody, $22 \mathrm{C} 10$, as early as three hours after pupariation and within the next five hours all $\mathrm{JO}$ neurons appear, loosely organized into three clusters, j1, j2 and je (Lienhard and Stocker, 1991). Such clustering is no longer evident in the fully differentiated adult antenna. Interestingly, the early neurons in the j1 cluster stain more lightly with 22C10 than those in j2 and je (Lienhard and Stocker, 1991). Understanding whether this stain- ing pattern is related to the distinction between triply and doubly innervated neurons, or to the cytoplasmic differential electron density between the two neurons of a given scolopidium (Todi et al., 2004, Yack, 2004), will require a more detailed characterization of the cell division patterns of $\mathrm{JO}$ precursors as well as a careful clonal analysis of all the cell types.

In contrast to $\mathrm{JO}, \mathrm{fCHO}$ consists of $\sim 71-74$ scolopidial units (Shanbhag et al., 1992). In the adult leg, these scolopidia are clustered into a large ventral group of about 32 scolopidia and two central groups of 14 and 25-28 scolopidia. While the ventral cluster makes distal attachments with the inner cuticle, the two central clusters attach apically to muscle group membranes instead of to cuticle (Shanbhag et al., 1992). Each $\mathrm{fCHO}$ scolopidium contains two neurons, one being more electrondense than the other, as also described for JO. However, no triply innervated scolopidia are seen. The genetic mechanisms in the early development of $\mathrm{fCHO}$ SOPs have been studied in some detail, though the post-specification events that give rise to the three separate clusters have yet to be scrutinized. In apparent contrast with the $\mathrm{JO}$, the $\mathrm{fCHO}$ scolopidia arise through reiterative recruitment of SOPs from the relatively small patch of atoexpressing proneural cluster cells (zur Lage and Jarman, 1999, zur Lage et al., 2004). This recruitment is achieved through EGF signaling by nascent SOPs to the overlying proneural cluster. This signaling antagonizes Notch-mediated lateral inhibition, permit-

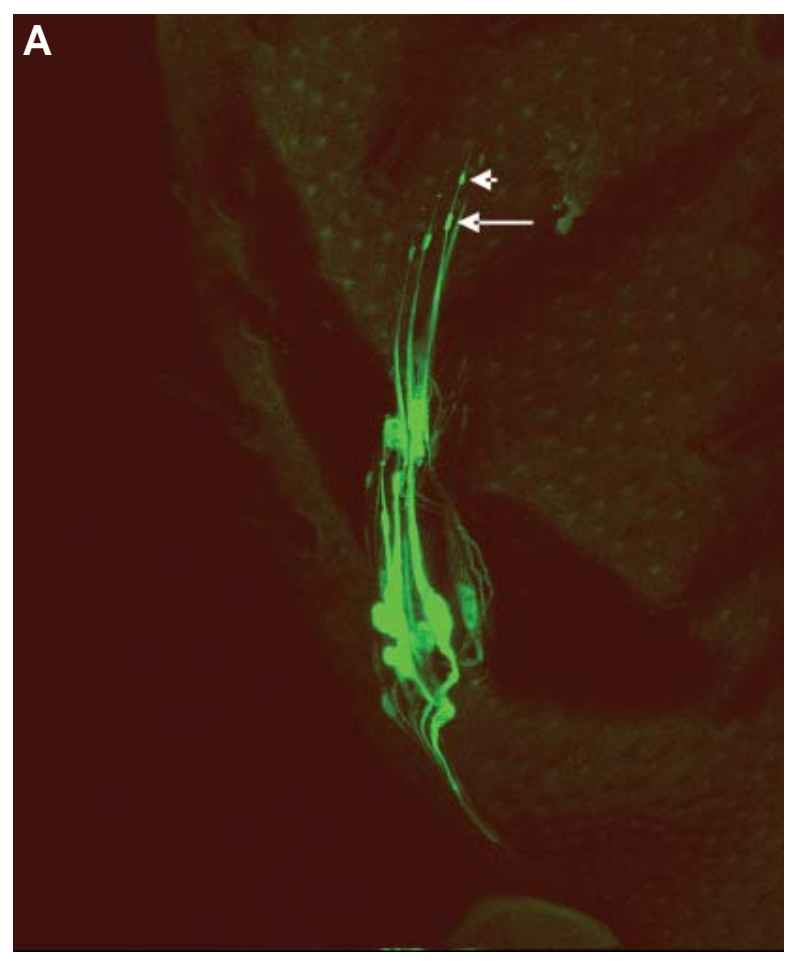

\section{B}

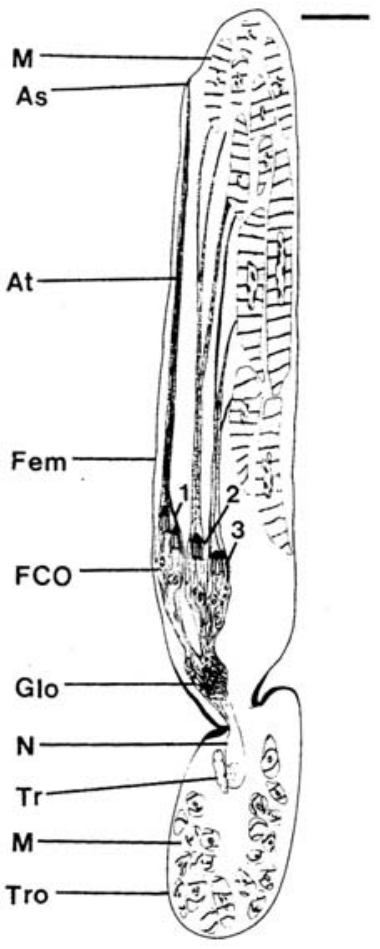

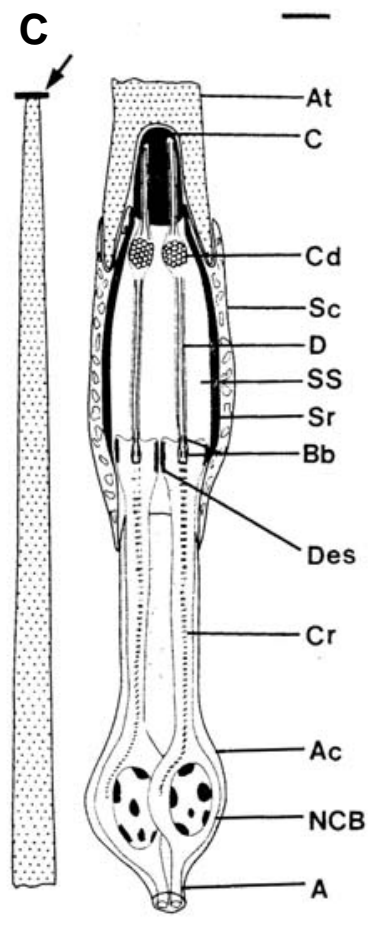

Fig. 2. Drosophila femoral chordotonal organ. (A) Proximal femur of a fly in which JO15-Gal4 drives UAS-GFP expression sporadically in a few neurons of $\mathrm{fCHO}$. The inner dendritic segment ends at the basal body (arrow). The outer dendritic segment is a cilium extending from the basal body and includes the ciliary dilation (arrowhead). (B) Schematic drawing through the femur (Fem) and trochanter (Tro) of the leg, showing the arrangement of 3 groups of scolopidia. Scale bar, 50 microns. (C) Detailed drawing of a fCHO scolopidium from distal attachment (arrow) to the level of the axon (labeled A). The attachment cell fragment on the left is drawn at 1/4 scale compared to the rest of the scolopidium on the right. Abbreviations: $A$, axon; Ac, accessory cell; As, attachment site; At, attachment cell; Bb, basal bodies; $C$, dendritic cap; Cd, ciliary dilation; Cr, ciliary root; $D$, dendritic outer segment; Des, desmosome; Fem, femur; Glo, glomerulus; $M$, muscle; N, nerve; NCB, nerve cell body; Sc, scolopale cell; Sr, scolopale rod; SS, scolopale space; Tr, trachea; Tro, trochanter. Scale bar, 1 micron. (B,C) are reprinted from Shanbhag (1992) with permission from Elsevier. 
ting persistent expression of the proneural gene ato within the cluster as well as facilitating recruitment of additional SOPs from the cluster. This elegant mechanism has not been described for $\mathrm{JO}$, despite its larger numbers of scolopidia. If indeed there is EGF receptor mediated recruitment of SOPs in $\mathrm{JO}$, it is likely to be much less extensive than in $\mathrm{fCHO}$, as the a 2 ring of atoexpression in the imaginal disk is also broader at the outset, likely generating more SOPs, perhaps even all of them, during a single round of SOP specification. However, instead of increasing SOP number for $\mathrm{JO}$, recruitment could underlie the multiple innervation of scolopidia. There is precedent for this in the olfactory sensillae in a3 where different neurons (some of which are derived from atoexpressing SOPs) within a sensillum are recruited as versus clonally derived (Sen et al., 2003). Experiments that address the lineages and the possibility of recruitment in $\mathrm{JO}$ development are still lacking.

The larval Ich5 consists of five scolopidial units. Not only do these $\mathrm{CHO}$ differ from $\mathrm{JO}$ and $\mathrm{fCHO}$ in scolopidial number, but the cellular composition of these scolopidia differs as well. Ich5 is the only Drosophila $\mathrm{CHO}$ for which the entire cell lineage and division patterns have been elucidated (Brewster and Bodmer, 1995). For Ich5, each scolopidium consists of four cells derived by asymmetric cell division from a single sense organ precursor (SOP). These are: a neuron, a scolopale cell, a ligament cell and a cap cell. In addition, each SOP of Ich5 gives rise to a single epidermal cell. Using clonal analysis, Brewster and Bodmer (1995) showed that one daughter cell produced by the first division of each lch5 SOP goes on to generate the cap cell and an ectodermal cell, while the other daughter first spawns the ligament cell, followed by the scolopale cell and the neuron. A variation on this lineage pattern is seen in the ventral chordotonal pair, vchA and vchB, where the prospective neuron divides further to cast off an additional cell which becomes a multidendritic neuron that differentiates without further association with the mature scolopidium.

Using arguments of genetic and developmental homology in lineage relationships, Lai and Orgogozo (2004) suggest that sense organs are derived from an ancestral sense organ type and that the lineages of modern Drosophila sense organs show variations of this common pattern. Thus, the ectodermal cell that arises from the embryonic chordotonal lineage may correspond to the cell in external sensory lineages that makes the external structure-the hair shaft of bristle organs or dome of the campaniform sensillum. In this model, this cell in $\mathrm{CHO}$ s is involved in the epithelium in scolopidial attachment instead of elaborating an external structure.

From the discussion so far, it would seem that embryonic $\mathrm{CHOs}$ are singly innervated while adult $\mathrm{CHO}$ are multiply innervated. Interestingly, however, the Wheeler's organ is an adult $\mathrm{CHO}$ whose scolopidia have only a single neuron (Elliott et al., 2005). So the number of neurons per scolopidium is a flexible parameter in the adult that may, under selection, change to whatever confers maximal physiological advantages.

Furthermore, whether additional, non-CHO neurons arise out of $\mathrm{CHO}$ lineages in adults as they do in embryos has not been well studied. In a2 and femur, there have been no neurons described
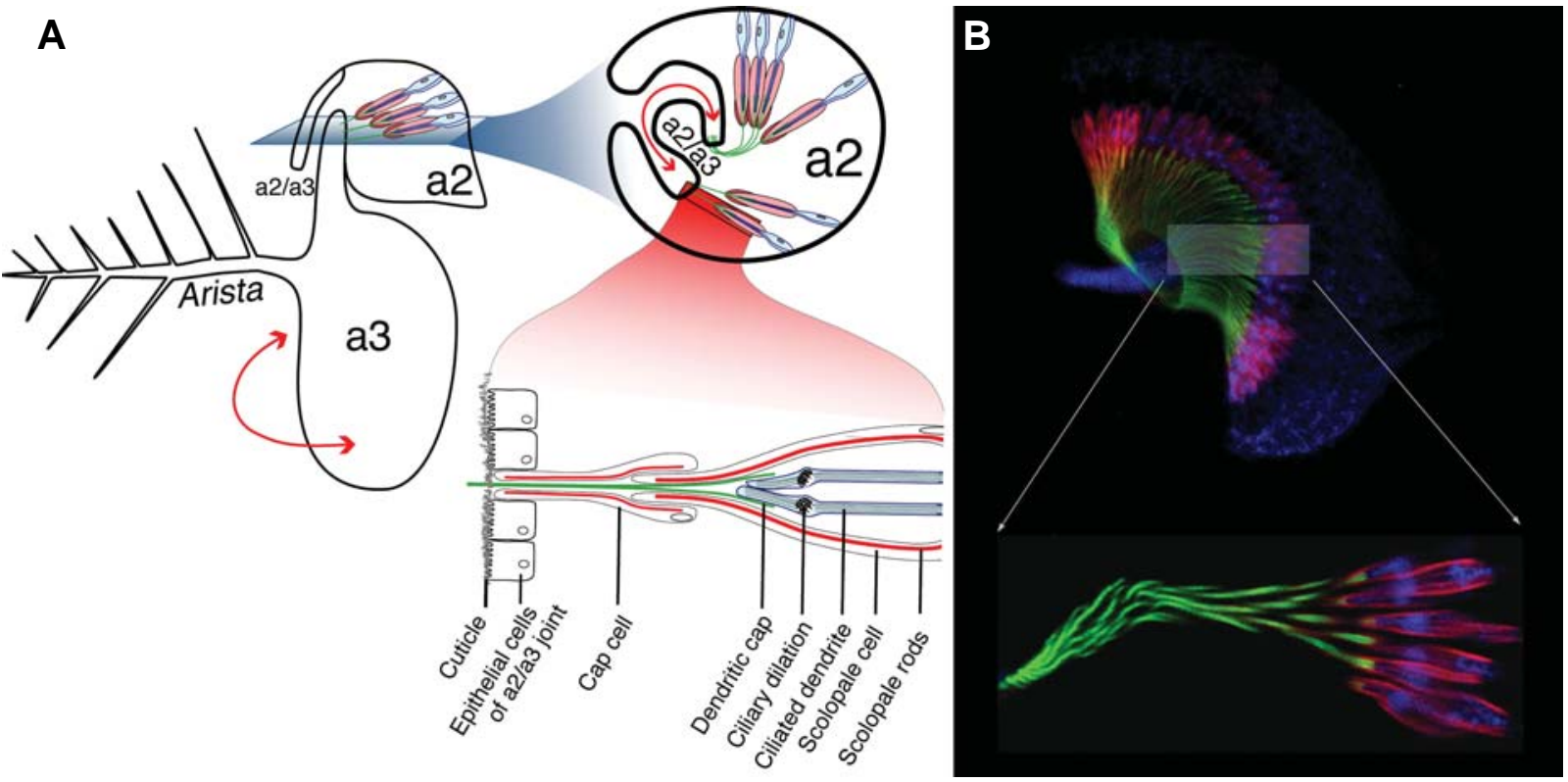

Fig. 3. Johnston's organ in Drosophila. (A) Schematic drawing of the Drosophila antenna and the sensory units of Johnston's organ. Acoustic activation of the arista causes rotation (doubled-headed red arrow) of antennal segment a3 relative to a2 at the a2/a3 joint. Cross-sectional view through a2 shows the arrangement of scolopidia with apical attachments at the joint. Expanded view of the distal half of one scolopidium shows the arrangement of cellular components in relation to the cuticle, the tubular structure of the extracellular dendritic cap (green) enclosing the tips of the ciliated outer dendritic segments of the neurons and the thick actin-based rods (red) in the scolopale and cap cells. (B) Confocal image of pupal antenna expressing the GFP-NompA protein in the dendritic cap (green), counterstained with Cy3-phalloidin (red) to reveal the scolopale rods in the scolopale cells and cap cells and stained with anti-horseradish peroxidase to label the neuronal membranes (blue). Inset shows higher magnification optical section of several scolopidia. 
that would be obvious candidates, so this mechanism would require migration of such neurons to other parts of-or even out of-the limb. This is possible but not likely. However, development of the adult abdominal and thoracic $\mathrm{CHOs}$ has not been studied well enough to either favor or disfavor this mechanism. In any of these cases, clonal analysis would provide the answers.

The apical ends of chordotonal neurons are associated with a dendritic cap, an extracellular matrix structure whose morphology can take one of two major forms (reviewed by Field and Matheson, 1998, Yack, 2004). In one form, the mononematic type, the major connection between the cuticular (or muscle membrane) attachment site and the cilium is a microtubule-rich attachment cell. The electron-dense extracellular material is compact and localizes primarily at the junction between the cilium and the attachment cell. In Drosophila, the Ich5 scolopidia are of the mononematic type, as are the $\mathrm{fCHO}$ (Shanbhag et al., 1992). In the second, amphinematic, type, the extracellular material of the cap forms a long hollow tube that encloses the ciliary tips and extends all the way into the cuticle at the attachment site. The Drosophila JO scolopidia are clearly amphinematic by this criterion. The attachment cell, or cap cell, in this case contains some microtubules, but also contains actin-rich "scolopale rods" like those present in the scolopale cell. The functional significance of the morphological differences between mononematic and amphinematic scolopidia is not clear but it has been suggested that they confer different viscoelastic properties upon the sensory units (Moulins, 1976, Yack, 2004).

Formation of cuticular elements at the JO scolopidial attachment sites at the a2/a3 joint is reported to be defective in the ato mutant (Göpfert et al., 2002). These cuticular elements may depend directly on ato-mediated specification, for example by secretion from putative ectodermal cells that may arise from the chordotonal lineage. Alternatively, these elements may depend on ato indirectly and be induced, genetically or even mechanically, by the associated scolopidia. These issues may be clarified by careful lineage analysis together with investigation of mutants that affect this process more specifically (such as perhaps ctand salm/saln).

$\mathrm{JO}$ is used for hearing, while $\mathrm{fCHO}$ and $\mathrm{Ich} 5$ are proprioceptive. However, it is worth noting that in some insects a subset of $\mathrm{fCHOs}$ or other $\mathrm{CHOs}$ are modified for hearing. This developmental and evolutionary flexibility of different $\mathrm{CHO}$ substrates to become adapted for hearing is exemplified by the fact that insect auditory organs, whether flagellar or tympanal, have been described in a wide variety of anatomical locations (reviewed by Hoy, 1998, Yager, 1999 and others). Comparative studies that examine properties of transition from proprioceptive to auditory function suggest that these changes can occur relatively quickly in narrow lineages (see for example Boyan, 1993, Boyan, 1998, van Staaden and Römer, 1998).

From a developmental genetic perspective, JO exhibits both similarities to and differences from other $\mathrm{CHOs}$. For instance, the SOPs of all DrosophilaCHOs, including JO, are specified through the activity of the proneural gene ato. However, three genes that inhibit $\mathrm{CHO}$ differentiation elsewhere in the Drosophila body, spalt-major (salm), spalt-related (sall) and cut (ct), are required for normal development and function of JO.

Both salm/ salrand ctmutants are completely deaf (Dong et al., 2003, Ebacher et al., 2007). The zinc-finger transcription factors encoded by salmand salmormally are expressed in the oenocytes surrounding Ich5. In the absence of $\mathrm{salm} / \mathrm{salrfunction}$, the number of scolopidia in Ich5 increases at the expense of oenocytes. It has been proposed that salm and salr function in oenocyte precursors both downstream of and in parallel to EGF signaling. In the absence of $\mathrm{salm} / \mathrm{sal}$ (rfunction, the EGF signal is interpreted as a differentiation cue for secondary Ich5 SOPs. As described above, in $\mathrm{fCHOs,} \mathrm{EGF} \mathrm{signaling} \mathrm{also} \mathrm{plays} \mathrm{a} \mathrm{critical} \mathrm{role} \mathrm{and} \mathrm{is}$ required for the recruitment of secondary SOPs. In marked contrast to their role in Ich5 differentiation, salm and salr are essential to JO differentiation and maintenance (Dong et al., 2003). In salm/salr mutant antennae, JO differentiates abnormally, then degenerates. salmand salrare expressed in both the epidermal precursors of a2 and the SOPs. In salm/ salr mutant antennae, the a2 cuticle and the a2/a3 joint to which JO scolopidia attach are defective. It remains unknown whether the failure of $\mathrm{JO}$ scolopidia to make proper attachments leads to their degeneration in salm/ salrmutants or whether there are intrinsic defects in the scolopidia themselves in these mutants.

ctencodes the Drosophilahomolog of human CAAT-displacement protein, a cell cycle-regulated homeodomain transcription factor. In the embryo, cthas well-studied roles in multiple dendritic (md) neurons and in external sensory (ES) organs. In md neurons, the higher levels of $c t$ expression correspond to more elaborate dendritic arborizations (Grueber et al., 2003). In ES organs, ctplays a role in fate specification and in the absence of ct function, some ES organs are transformed to $\mathrm{CHO}$ fates (Bodmer et al., 1987, Merritt, 1997). Furthermore, misexpression of $c t$ in developing embryonic $\mathrm{CHO}$ transforms them into ES organs. It therefore is surprising that $c t$ is required for normal JO differentiation and that in ct mutants the JO scolopidial units differentiate abnormally and subsequently degenerate (Ebacher et al., 2007). Similar to salm/salr, ct is expressed in both the epidermal precursors of a2 and the JO SOPs and ct mutants exhibit defects in the a2/a3 joint cuticle. However, in the case of $c t$, specific subcellular defects have been observed in both $\mathrm{JO}$ neurons and scolopale cells by transmission electron microscopy (Eberl, unpublished). Because ct neither regulates nor is regulated by ato, salm and salr in the developing $\mathrm{JO}$, it has been proposed that $\mathrm{Ct}$ functions in conjunction with the transcription factors encoded by these genes to regulate as yet unidentified targets required for $\mathrm{JO}$ development, maintenance and function (Ebacher et al., 2007).

There has long been evidence of diversity among Ich5 and $\mathrm{fCHO}$ scolopidia, but insights into the molecular diversity among $\mathrm{JO}$ scolopidia have only recently come to light. For instance, a monoclonal antibody, 49C4, labels only the posterior four scolopidia of Ich5, indicating the presence of a cellular antigen in those four that is missing from the most anterior scolopidium (Bodmer et al., 1987). One Ich5 scolopidium often remains in the ato mutant (Jarman et al., 1993, zur Lage et al., 1997); whether this is the 49C4 negative scolopidium is not clear. In addition, because two of the five units arise from EGFR-mediated signaling through the rho and argos genes (Okabe and Okano, 1997, zur Lage et al., 1997), these two may be molecularly unique, even though no known markers label them differentially. Axonal projections from Ich5 have been mapped and also show some diversity (Merritt and Whitington, 1995, Smith and Shepherd, 1996, Merritt, 1997, Schrader and Merritt, 2000). In the fCHO, several Gal4 lines (see 
Brand and Perrimon (1993) and Duffy (2002) for explanation of these genetic tools) express in different subsets of neurons, with different projection patterns into the thoracic ganglia (Phillis et al., 1996, Reddy et al., 1997, Murphey et al., 1999). It is not known whether any of these also express in $\mathrm{JO}$. Before leaving the leg to enter the thoracic ganglia, the $\mathrm{fCHO}$ axons form a glomerulus (Shanbhag et al., 1992), an arrangement that is not seen in JO. In $\mathrm{JO}$, one enhancer trap line, $\mathrm{J} 21.17$, stains only a subset of neurons (Sharma et al., 2002, Sivan-Loukianova and Eberl, 2005). This line, when converted into a Gal4 line (JO15), was shown to express in $145 \pm 2$ neurons (Kamikouchi et al., 2006). Another Gal4 line, identified in a screen for mutations that affect gravitaxis, inserted into the yuri gagarin gene, is reported to express in about $40 \mathrm{JO}$ neurons (Armstrong etal., 2006, Baker etal., 2007). In a systematic Gal4 screen, Kamikouchi et al. (2006) characterized 17 Gal4 insertions with expression in JO. These express in several subset patterns of $\mathrm{JO}$ neurons and project into five major zones in the brain. Comprehensive analysis of these lines, as well as single cell labeled clones, defined 19 subregions of projections. Thus, in addition to the important contribution towards understanding molecular diversity in $\mathrm{JO}$, the Kamikouchi study also systematically documents diversity in projection patterns of $\mathrm{JO}$ neurons using these different lines. This diversity points to one of the possible functional consequences of molecular diversity, namely finding diverse targets in the brain. The new projection map will set the stage for beginning to understand the relationship between the diversity of JO scolopidia, neural circuitry and behavioral biology.

\section{How the Drosophila antenna works as an ear}

Acoustic physics of insect songs and hearing have been described by Bennet-Clark (1971). Relevant particularly to insects like Drosophilathat use their hearing only very close to the source, airborne sound has two energy components, particle velocity (PV, also called particle displacement) and sound pressure. At a large distance from the source (in the so-called acoustic far-field), these two components are in phase and most of the energy is in the pressure component. The design of tympanal ears such as those of crickets, katydids and cicadas, which use long-distance acoustic communication, are optimized to respond to the pressure component. In contrast, close to the sound source (in the acoustic nearfield), the PV and pressure components become increasingly out of phase, reaching $90^{\circ}$ out of phase at the source. Perhaps more importantly, in this range, PV predominates over the pressure component. Specifically, PV intensity decreases as a function of the cubic root of the distance from the source, while pressure falls off only with the square root of the distance (see also Kalmijn (1997) for a review of these principles in the context of aquatic animal hearing). Thus, auditory systems that respond to the PV component are most sensitive at close range. To respond to $\mathrm{PV}, \mathrm{a}$ receiving structure should be easily displaced with the moving air mass; in Drosophila this structure is the arista. Sound-induced aristal movement imposes a rotational force on the joint between antennal segments 2 and 3 (a2/a3 joint) (Eberl et al., 2000, Göpfert and Robert, 2001b, Göpfert and Robert, 2002). Joint flexion is then transduced by JO (Eberl et al., 2000).

Contrary to long-held views that sensory cilia, which lack the central pair of microtubules, are non-motile, JO not only senses the movements, but actively generates motion in the antenna (Göpfert and Robert, 2003). This motion generation, which may be considered analogous to the mammalian cochlear amplifier, serves to optimize sensitivity to the frequency components in the courtship song, as well as to broaden the dynamic range of hearing so that low intensity sounds are amplified while high intensity sounds are damped. Measurement of the power output of the JO neurons has produced estimates of about 19 zJ (Göpfert et al., 2005).

These considerations suggest that there is an important interplay between $\mathrm{CHO}$ physiological properties, cuticular elasticity and shape, as well as the size/shape/arrangement of distal antennal segments. These factors will impinge on the various component forces discussed by Todi et al. (2004) that maintain the JO as a tensioned system. When considering these factors for Drosophila, mosquito and honeybee (Tsujiuchi et al., 2007), for example, there may emerge a relationship between number/diversity and physiology of scolopidia with acoustic sensitivity; however, many more species (and mutants) need to be studied and other interacting factors need to be measured quantitatively to understand their significance in a systematic way. Finally, while outside the scope of this review, it is important to remember that insects with tympanal ears, responding to far-field sound, face and solve the same spectrum of issues.

Despite much progress in Drosophila JO biology, the precise sensory mechanism is still not clear in molecular detail. That the sensory mechanism localizes to the cilium is supported by the fact that mutations in genes that affect $\mathrm{JO}$ ciliary development and morphology lead to deafness. These include components of intraflagellar transport (IFT) such as the anterograde kinesin motor subunits kinesin-like protein 64D(K/p64D) and the kinesin associated protein (DmKAP) (Sarpal et al., 2003), the retrograde cytoplasmic dynein motor encoded by beethoven (btv) (Eberl et al., 2000, Sharma et al., in preparation), the anterograde IFT-B particle proteins no mechanoreceptor potential $B$ (nompB) (Han et al., 2003), outer segment protein 2 (oseg2, also called osm-1) and outer segment protein 5 (oseg5) (Avidor-Reiss et al., 2004), the retrograde IFT-A particle proteins oseg1 and reduced mechanoreceptor potential A (rempA; also called oseg3) (Avidor-Reiss et al., 2004, Lee et al., in preparation) and the ciliary transcription regulator Drosophila regulatory factor $X(d R f x)$ (Durand et al., 2000, Dubruille et al., 2002). Mutations that appear to affect the ciliary axoneme also lead to deafness. These include touch insensitive larva $B$ (tilB) and smetana (smet) (Kernan et al., 1994, Eberl et al., 2000, Todi et al., 2004). Others, such as uncoordinated(und) and the Drosophila pericentrin-like protein ( D-PLP), affect basal bodies or centrioles and disrupt hearing (Baker et al., 2004, Martinez-Campos et al., 2004). Finally, mutations that disrupt the physical connection between the a2/a3 joint and the sensory cilia, including no mechanoreceptor potential $A$ (nompA) (Chung et al., 2001), a component of the extracellular dendritic cap tube necessary for association of the cilium with the cap, and the myosin VIIA motor protein encoded by crinkled (ck), which is required for association of the dendritic cap with the cuticle (Todi et al., 2005), lead to deafness.

To complement these morphological studies, a subset of these mutations has been studied for their effects on non-linear mechanics and motion generation in the Drosophila antenna. All mutants tested affected the non-linear mechanics by partially or completely collapsing to linear mechanical systems (Göpfert and Robert, 2003). Interestingly, the resonant frequency at which the linearity 
settles in each mutant is related to the stiffness of the mechanical system, a function of how much of the connection to the cilium is lost. Thus, tilB retains all major structures and connections and collapses to linearity at about $800 \mathrm{~Hz}$, just as is seen in a dead wildtype fly; btv mutants, which lose much structural integrity (but not all connections) between cilia and dendritic caps, linearize at about $600 \mathrm{~Hz}$; nompA mutants, in which all cilia are detached from the dendritic caps, linearize at about $400 \mathrm{~Hz}$. These findings are consistent with a ciliary location for the mechanism(s) that detects movement and generates motion in the antenna.

Some details of the sensory mechanism of hearing have been elucidated recently at the molecular level. In particular, three members of the TRP channel family are involved in hearing, though their precise roles are not yet clear. The nanchung (nan) and inactive (iav) genes encode a pair of TRPV channels that are localized to the ciliary membrane and are mutually dependent for localization and absolutely required for hearing (Kim et al., 2003, Gong et al., 2004). The no mechanoreceptor potential C (nompC) gene, a member of the TRPN subfamily required for bristle organ mechanotransduction (Walker et al., 2000), contributes to auditory sensitivity, but its absence does not completely abolish hearing (Eberl et al., 2000), as measured by afferent auditory responses in the antennal nerve. Using measurements of non-linear mechanics in the antenna, Göpfert et al. (2006) argue that NompC is required both for a feedback loop in this non-linear amplification, but also for self-sustained spontaneous motion generation (analogous to spontaneous otoacoustic emissions in the mammalian ear). In contrast, nan and iav mutations increase the amplitudes of spontaneous oscillations of the antenna. Using double mutant combinations, in which both the sound-induced motions and the spontaneous oscillations of nanare suppressed by nompC , they present a model in which 1) Nan and lav control the activity of the NompC-mediated amplificatory feedback and 2) NompC is a candidate mechanotransducer, but 3 ) one or more additional transducers must exist to explain residual afferent responses in the nompC mutants. In this model, the Nan/lav channels are required for the propagation of the afferent sensory response, but not for the core mechanism of the amplificatory feedback mechanism (rather, only to modulate its gain). Further studies are required to test this model and to identify additional components in the amplification mechanism and the mechanosensory transduction mechanism, including the additional mechanotransducer channels. The findings to date suggest however that these two mechanisms are likely to be intricately and intimately intertwined.

\section{What we don't know}

In addition to the issues discussed above, other important questions remain about both $\mathrm{JO}$ development and $\mathrm{JO}$ function. For instance, it remains unclear why JO scolopidia possess multiple neurons and from where these neurons derive. Since $\mathrm{fCHOs}$ also have multiple neurons, increased neuron number is not correlated simply with a change from proprioception to audition. However, it is possible that possessing multiple neurons increases $\mathrm{CHO}$ sensitivity by increasing the likelihood of a unitary response. This would be useful for more precisely encoding sound intensity, particularly near thresholds. Alternatively, since increasing the number of neurons increases the density of cilia, the energy for the oscillatory mechanism would also be increased. That the number of neurons in $\mathrm{JO}$ scolopidia is not uniform suggests that doubly and triply innervated scolopidia possess distinct functions. Whether these correlate cleanly with the functions currently attributed to $\mathrm{JO}$ - sensing wind currents, gravity sensation and hearing-remains to be seen, but seems unlikely.

What does seem likely is that the differently innervated scolopidia respond to different parameters of sound. Scolopidial tuning probably is significantly more refined than this, however, as illustrated by the striking gene expression differences and differences in electron density among JO neurons. The consequences of these gene expression differences and how they are achieved are likely to be fruitful avenues of future research. The nature of the organelles contributing to variation in electron density among $\mathrm{JO}$ neurons is likely to provide insight into $\mathrm{JO}$ function, as well as new directions for JO research.

Related issues are whether the various neurons of a particular scolopidium are clonally related, how $\mathrm{JO}$ neurons are related to other cells of the scolopidium such as the scolopale cell and the cap and whether there is recruitment of JO SOPs. Addressing these questions is essential to our understanding of $\mathrm{JO}$ specification and differentiation.

The developmental and functional consequences of genetic differences between $\mathrm{JO}$ and other $\mathrm{CHO}$ remain unexplored and will undoubtedly be a significant area of future research. That genes involved in inhibiting $\mathrm{CHO}$ development elsewhere are required in $\mathrm{JO}$ is both astonishing and baffling. Whether genes such as salm, salr and ct regulate JO-specific targets is an important-and testable-question. If JO-specific target genes can be identified, this in turn would be likely to provide insights into how, at the cytoskeletal and/or organelle level, JO neurons differ from neurons in other sensory structures.

Finally, the evolutionary constraints on $\mathrm{CHO}$ plasticity due to the physical properties of sound may have important implications in terms of scolopidial specializations. In particular, the specializations that favor reception of near-field sound, such as JO, may be very different from those that favor performance of far-field sound detection in tympanal $\mathrm{CHOs}$. Evolutionary selection is exerted via adaptive advantages conferred by performance enhancement. In this context, transformation between the far-field and near-field modes may be difficult without first losing function of the previous mode. Such constraints have been considered in vertebrate inner ear development and evolution during the transition from an aquatic to a terrestrial lifestyle (Fritzsch, 1999). The many advances toward understanding the molecular function and development of Drosophila auditory organ in the last ten years are starting to provide the tools to begin approaching such important evolutionary questions.

\section{Acknowledgements}

We are grateful to Matt Miller for the images in Figures $1 A$ and $2 A$, to Dominic Ebacher for those in Figure $3 B$ and to Sokol Todi for the drawing in Figure $3 A$. Our research is supported by NIH grants DC004848 to DFE and DC008154 to GBF.

\section{References}

ARMSTRONG, J.D., TEXADA, M.J., MUNJAAL, R., BAKER, D.A. and BECKINGHAM, K.M. (2006). Gravitaxis in Drosophila melanogaster. a forward genetic screen. Genes Brain Behav. 5: 222-239.

AVIDOR-REISS, T., MAER, A.M., KOUNDAKJIAN, E., POLYANOVSKY, A., KEIL, 
T., SUBRAMANIAM, S. and ZUKER, C.S. (2004). Decoding cilia function: defining specialized genes required for compartmentalized cilia biogenesis. Cel/117: 527-539.

BAKER, D.A., BECKINGHAM, K.M. and ARMSTRONG, J.D. (2007). Functional dissection of the neural substrates for gravitaxic maze behavior in Drosophila melanogaster. J. Comp. Neurol. 501: 756-764.

BAKER, J.D., ADHIKARAKUNNATHU, S. and KERNAN, M.J. (2004). Mechanosensory-defective, male-sterile unc mutants identify a novel basal body protein required for ciliogenesis in Drosophila. Development 131: 34113422.

BENNET-CLARK, H.C. (1971). Acoustics of insect song. Nature 234: 255-259.

BODMER, R., BARBEL, S., SHEPHERD, S., JACK, J.W., JAN, L.Y. and JAN, Y.N. (1987). Transformation of sensory organs by mutations of the cut locus of $D$. melanogaster. Cel/51: 293-307.

BOEKHOFF-FALK, G. (2005). Hearing in Drosophila. development of Johnston's organ and emerging parallels to vertebrate ear development. Dev. Dynam. 232: 550-558.

BOO, K.S. and RICHARDS, A.G. (1975a). Fine structure of scolopidia in Johnston's organ of female Aedes aegypticompared with that of the male. J. Insect Physiol. 21: 1129-1139.

BOO, K.S. and RICHARDS, A.G. (1975b). Fine structure of the scolopidia in the Johnston's organ of male Aedes aegypti(L.) (Diptera: Culicidae). Int. J. Insect Morphol. Embryol. 4: 549-566.

BOYAN, G.S. (1993). Another look at insect audition: the tympanic receptors as an evolutionary specialization of the chordotonal system. J. Insect Physiol. 39: 187-200.

BOYAN, G.S. (1998). Development of the insect auditory system. In Comparative Hearing: Insects, vol. 10 (ed. Hoy, R.R, Popper, A.N. and Fay, R.R.). Springer, New York, pp.97-138.

BRAND, A.H. and PERRIMON, N. (1993). Targeted gene expression as a means of altering cell fates and generating dominant phenotypes. Development 118 : 401-415.

BREWSTER, R. and BODMER, R. (1995). Origin and specification of type II sensory neurons in Drosophila. Development 121: 2923-2936.

BUDICK, S.A. and DICKINSON, M.H. (2006). Free-flight responses of Drosophila melanogaster to attractive odors. J. Exp. Biol. 209: 3001-3017.

BURKHARDT, D. (1960). Action potentials in the antennae of the blowfly (Calliphora erythrocephala) during mechanical stimulation. J. Insect Physiol. 4: 138145.

CALDWELL, J.C. and EBERL, D.F. (2002). Towards a molecular understanding of Drosophila hearing. J. Neurobiol. 53: 172-189.

CALDWELL, J.C., MILLER, M.M., WING, S., SOLL, D.R. and EBERL, D.F. (2003). Dynamic analysis of larval locomotion in Drosophilachordotonal organ mutants. Proc. Natl. Acad. Sci. USA 100: 16053-16058.

CHUNG, Y.D., ZHU, J., HAN, Y.-G. and KERNAN, M.J. (2001). nompA encodes a PNS-specific, ZP domain protein required to connect mechanosensory dendrites to sensory structures. Neuron 29: 415-428.

DONG, P.D.S., TODI, S.V., EBERL, D.F. and BOEKHOFF-FALK, G. (2003). Drosophila spalt/spalt-related mutants exhibit Townes-Brocks' syndrome phenotypes. Proc. Natl. Acad. Sci. USA 100: 10293-10298.

DUBRUILLE, R., LAURENÇON, A., VANDAELE, C., SHISHIDO, E., COULONBUBLEX, M., SWOBODA, P., COUBLE, P., KERNAN, M. and DURAND, B. (2002). Drosophila regulatory factor $X$ is necessary for ciliated sensory neuron differentiation. Development 129: 5487-5498.

DUFFY, J.B. (2002). GAL4 system in Drosophila: a fly geneticist's Swiss army knife. Genesis 34: 1-15.

DURAND, B., VANDAELE, C., SPENCER, D., PANTALACCI, S. and COUBLE, P. (2000). Cloning and characterization of $d R F X$, the Drosophila member of the RFX family of transcription factors. Gene 246: 285-293.

EBACHER, D.J.S., TODI, S.V., EBERL, D.F. and BOEKHOFF-FALK, G. (2007). cut mutant Drosophilaauditory organs differentiate abnormally and degenerate. Fly 1: $86-94$.

EBERL, D.F. (1999). Feeling the vibes: chordotonal mechanisms in insect hearing. Curr. Opin. Neurobiol. 9: 389-393.

EBERL, D.F., HARDY, R.W. and KERNAN, M. (2000). Genetically similar transduc- tion mechanisms for touch and hearing in Drosophila. J. Neurosci. 20: 59815988.

ELLIOTT, S.L., CULLEN, C.F., WROBEL, N., KERNAN, M.J. and OHKURA, H. (2005). EB1 is essential during Drosophila development and plays a crucial role in the integrity of chordotonal mechanosensory organs. Mol. Biol. Cel/16: 891901.

FIELD, L.H. and MATHESON, T. (1998). Chordotonal organs of insects. In Adv. Insect Physiol., vol. 27 (ed. EVANS, P. D.). Academic Press, San Diego, pp.1228.

FRITZSCH, B. (1999). Hearing in two worlds: Theoretical and actual adaptive changes of the aquatic and terrestrial ear for sound reception. In Comparative Hearing: Fishes and Amphibians, vol. 11 (ed. Fay, R.R. and Popper, A.N.). Springer, New York, pp.15-42.

GIBSON, G. and RUSSELL, I. (2006). Flying in tune: sexual recognition in mosquitoes. Curr. Biol. 16: 1311-1316.

GONG, Z., SON, W., CHUNG, Y.D., KIM, J., SHIN, D.W., MCCLUNG, C.A., LEE, Y., LEE, H.W., CHANG, D.-J., KAANG, B.-K. et al. (2004). Two interdependent TRPV channel subunits, inactive and nanchung, mediate hearing in Drosophila. J. Neurosci. 24: 9059-9066.

GÖPFERT, M.C., ALBERT, J.T., NADROWSKI, A. and KAMIKOUCHI, A. (2006). Specification of auditory sensitivity by DrosophilaTRP channels. Nature Neurosci. 9: 999-1000.

GÖPFERT, M.C., HUMPHRIS, A.D.L., ALBERT, J.T., ROBERT, D. and HENDRICH, O. (2005). Power gain exhibited by motile mechanosensory neurons in Drosophila ears. Proc. Natl. Acad. Sci. USA 102: 325-330.

GÖPFERT, M.C. and ROBERT, D. (2001a). Active auditory mechanics in mosquitoes. Proc. Roy. Soc. Lond. B268: 333-339.

GÖPFERT, M.C. and ROBERT, D. (2001b). Turning the key on Drosophilaaudition. Nature 411: 908.

GÖPFERT, M.C. and ROBERT, D. (2002). The mechanical basis of Drosophila audition. J. Exp. Biol. 205: 1199-1208.

GÖPFERT, M.C. and ROBERT, D. (2003). Motion generation by Drosophila mechanosensory neurons. Proc. Natt. Acad. Sci. USA 100: 5514-5519.

GÖPFERT, M.C., STOCKER, H. and ROBERT, D. (2002). atona/is required for exoskeletal joint formation in the Drosophila auditory system. Dev. Dynam. 225: 106-109.

GRONENBERG, W. and STRAUSFELD, N.J. (1990). Descending neurons supplying the neck and flight motor of Diptera: Physiological and anatomical characteristics. J. Comp. Neurol. 302: 973-991.

GRUEBER, W.B., JAN, L.Y. and JAN, Y.N. (2003). Different levels of the homeodomain protein Cut regulate distinct dendrite branching patterns of Drosophila multidendritic neurons. Cel/112: 805-818.

HAN, Y.-G., KWOK, B.H. and KERNAN, M.J. (2003). Intraflagellar transport is required in Drosophilato differentiate sensory cilia but not sperm. Curr. Biol. 13: 1679-1686.

HERTWECK, H. (1931). Anatomie und Variabilität des Nervensystems und der Sinnesorgane von Drosophila melanogaster (Meigen). Zeitschr. f. wiss. Zool. 139: 559-663.

HOY, R.R. (1998). Acute as a bug's ear: an informal discussion of hearing in insects. In Comparative Hearing: Insects, vol. 10 (ed. HOY, R. R.POPPER, A. N. and FAY, R. R.). Springer, New York, pp.1-17.

JACKSON, J.C. and ROBERT, D. (2006). Nonlinear auditory mechanism enhances female sounds for male mosquitoes. Proc. Natt. Acad. Sci. USA 103: 1673416739.

JARMAN, A.P. (2002). Studies of mechanosensation using the fly. Hum. Molec. Genet. 11: 1215-1218.

JARMAN, A.P., GRAU, Y., JAN, L.Y. and JAN, Y.N. (1993). atona/is a proneural gene that directs chordotonal organ formation in the Drosophila peripheral nervous system. Cel/73: 1307-1321.

JARMAN, A.P., SUN, Y., JAN, L.Y. and JAN, Y.N. (1995). Role of the proneural gene, atonal, in formation of Drosophila chordotonal organs and photoreceptors. Development 121: 2019-2030.

JERAM, S. and PABST, M.A. (1996). Johnston's organ and central organ in Nezara viridula (L.) (Heteroptera, Pentatomidae). Tissue \& Cel/28: 227-235.

JOHNSTON, J.S. (1982). Genetic variation for anemotaxis (wind-directed move- 
ment) in laboratory and wild-caught populations of Drosophila. Behav. Genet. 12: 281-293.

KALMIJN, A.J. (1997). Electric and near-field acoustic detection, a comparative study. Acta Physiol. Scand. Suppl. 638: 25-38.

KAMIKOUCHI, A., SHIMADA, T. and ITO, K. (2006). Comprehensive classification of auditory sensory projections in the brain of the fruit fly Drosophila melanogaster. J. Comp. Neurol. 499: 317-356.

KERNAN, M., COWAN, D. and ZUKER, C. (1994). Genetic dissection of mechanosensory transduction: mechanoreception-defective mutations of Drosophila. Neuron 12: 1195-1206.

KIM, J., CHUNG, Y.D., PARK, D.-Y., CHOI, S., SHIN, D.W., SOH, H., LEE, H.W., SON, W., YIM, J., PARK, C.-S. etal. (2003). A TRPV family ion channel required for hearing in Drosophila. Nature 424: 81-84.

LAI, E.C. and ORGOGOZO, V. (2004). A hidden program in Drosophila peripheral neurogenesis revealed: fundamental principles underlying sensory organ diversity. Dev. Biol. 269: 1-17.

LAKES-HARLAN, R., STÖLTING, H. and STUMPNER, A. (1999). Convergent evolution of insect hearing organs from a preadaptive structure. Proc. Roy. Soc. Lond. B266: 1161-1167.

LIENHARD, M.C. and STOCKER, R.F. (1991). The development of the sensory neuron pattern in the antennal disc of wild-type and mutant $\left(/ z^{3}, s s^{a}\right)$ Drosophila melanogaster. Development 112: 1063-1075.

MARTINEZ-CAMPOS, M., BASTO, R., BAKER, J., KERNAN, M. and RAFF, J.W. (2004). The Drosophila pericentrin-like protein is essential for cilia/flagella function, but appears to be dispensible for mitosis. J. Cell Biol. 165: 673-683.

MERRITT, D.J. (1997). Transformation of external sensilla to chordotonal sensilla in the cutmutant of Drosophila assessed by single-cell marking in the embryo and larva. Microsc. Res. Tech. 39: 492-505.

MERRITT, D.J. and WHITINGTON, P.M. (1995). Central projections of sensory neurons in the Drosophila embryo correlate with sensory modality, soma position and proneural gene function. J. Neurosci. 15: 1755-1767.

MILDE, J.J., SEYAN, H.S. and STRAUSFELD, N.J. (1987). The neck and motor system of the fly Calliphora erythrocephala. II. Sensory organization. J. Comp. Physiol. A 160: 225-238.

MILLER, A. (1950). The internal anatomy and histology of the imago of Drosophila melanogaster. In Biology of Drosophila, (ed. Demerec, M.). John Wiley \& Sons, New York, pp.420-534.

MOULINS, M. (1976). Ultrastructure of chordotonal organs. In Structure and function of proprioceptors in the invertebrates, (ed. Mill, P.J.). Chapman and Hall, London, pp.387-426.

MURPHEY, R.K., CARUCCIO, P.C., GETZINGER, M., WESTGATE, P.J. and PHILLIS, R.W. (1999). Dynein-dynactin function and sensory axon growth during Drosophila metamorphosis: a role for retrograde motors. Dev. Biol. 209: 86-97.

OKABE, M. and OKANO, H. (1997). Two-step induction of chordotonal organ precursors in Drosophila embryogenesis. Development 124: 1045-1053.

PHILLIS, R., STATTON, D., CARUCCIO, P. and MURPHEY, R.K. (1996). Mutations in the $8 \mathrm{kDa}$ dynein light chain gene disrupt sensory axon projections in the Drosophila imaginal CNS. Development 122: 2955-2963.

POWER, M.E. (1948). The thoracico-abdominal nervous system of an adult insect, Drosophila melanogaster. J. Comp. Neurol. 88: 347-409.

REDDY, S., JIN, P., TRIMARCHI, J., CARUCCIO, P., PHILLIS, R. and MURPHEY, R.K. (1997). Mutant molecular motors disrupt neural circuits in Drosophila. J. Neurobiol. 33: 711-723.

ROBERT, D. and GÖPFERT, M.C. (2002). Novel schemes for hearing and orientation in insects. Curr. Opin. Neurobiol. 12: 715-720.

SARPAL, R., TODI, S.V., SIVAN-LOUKIANOVA, E., SHIROLIKAR, S.,
SUBRAMANYAN, N., RAFF, E.C., ERICKSON, J.W., RAY, K. and EBERL, D.F. (2003). The Drosophila kinesin associated protein (DmKAP) interacts with the Kinesin II motor subunit KIp64D to assemble chordotonal organ sensory cilia but not sperm tails. Curr. Biol. 13: 1687-1696.

SCHRADER, S. and MERRITT, D.J. (2000). Central projections of Drosophila sensory neurons in the transition from embryo to larva. J. Comp. Neurol. 425: 34-44.

SEN, A., REDDY, G.V. and RODRIGUES, V. (2003). Combinatorial expression of Prospero, Seven-up and Elav identifies progenitor cell types during senseorgan differentiation in the Drosophila antenna. Dev. Biol. 254: 79-92.

SHANBHAG, S.R., SINGH, K. and SINGH, R.N. (1992). Ultrastructure of the femoral chordotonal organs and their novel synaptic organization in the legs of Drosophila melanogaster Meigen (Diptera: Drosophilidae). Int. J. Insect Morphol. Embryol. 21: 311-322.

SHARMA, Y., CHEUNG, U., LARSEN, E.W. and EBERL, D.F. (2002). pPTGAL, a convenient Gal4 P-element vector for testing expression of enhancer fragments in Drosophila. Genesis 34: 115-118.

SIVAN-LOUKIANOVA, E. and EBERL, D.F. (2005). Synaptic ultrastructure of Drosophila Johnston's organ axon terminals as revealed by an enhancer trap. J. Comp. Neurol. 491: 46-55.

SMITH, S.A. and SHEPHERD, D. (1996). Central afferent projections of proprioceptive sensory neurons in Drosophila revealed with the enhancer-trap technique. J. Comp. Neurol. 364: 311-323.

STRAUSFELD, N.J., SEYAN, H.S. and MILDE, J.J. (1987). The neck motor system of the fly Calliphora erythrocephala. I. Muscles and motor neurons. J. Comp. Physiol. A 160: 205-224.

TAUBER, E. and EBERL, D.F. (2001). Song production in auditory mutants of Drosophila: the role of sensory feedback. J. Comp. Physiol. A 187: 341-348.

TODI, S.V., FRANKE, J.D., KIEHART, D.P. and EBERL, D.F. (2005). Myosin VIIA defects, which underlie the Usher $1 B$ Syndrome in humans, lead to deafness in Drosophila. Curr. Biol. 15: 862-868.

TODI, S.V., SHARMA, Y. and EBERL, D.F. (2004). Anatomical and molecular design of the Drosophila antenna as a flagellar auditory organ. Microsc. Res. Tech. 63: 388-399.

TSUJIUCHI, S., SIVAN-LOUKIANOVA, E., EBERL, D.F., KITAGAWA, Y. and KADOWAKI, T. (2007). Dynamic range compression in the honey bee auditory system toward waggle dance sounds. PLOS ONE2: e234.

VAN STAADEN, M.J. and RÖMER, H. (1998). Evolutionary transition from stretch to hearing organs in ancient grasshoppers. Nature 394: 773-776.

WALKER, R.G., WILLINGHAM, A.T. and ZUKER, C.S. (2000). A Drosophila mechanosensory transduction channel. Science 287: 2229-2234.

YACK, J.E. (2004). The structure and function of auditory chordotonal organs in insects. Microsc. Res. Tech. 63: 315-337.

YAGER, D.D. (1999). Structure, development and evolution of insect auditory systems. Microsc. Res. Tech. 47: 380-400.

ZUR LAGE, P., JAN, Y.N. and JARMAN, A.P. (1997). Requirement for EGF receptor signalling in neural recruitment during formation of Drosophila chordotonal sense organ clusters. Curr. Biol. 7: 166-175.

ZUR LAGE, P. and JARMAN, A.P. (1999). Antagonism of EGFR and Notch signalling in the reiterative recruitment of Drosophila adult chordotonal sense organ precursors. Development 126: 3149-3157.

ZUR LAGE, P.I., POWELL, L.M., PRENTICE, D.R.A., MCLAUGHLIN, P. and JARMAN, A.P. (2004). EGF receptor signaling triggers recruitment of Drosophila sense organ precursors by stimulating proneural gene autoregulation. Dev. Cell/7: 687-696. 


\section{Related, previously published Int. J. Dev. Biol. articles}

See our Special Issue Ear Development edited by Fernando Giraldez and Bernd Fritzsch at: http://www.ijdb.ehu.es/web/contents.php?vol=51\&issue=6-7

See our Special Issue Developmental Morphodynamics edited by Richard Gordon and Lev Beloussov at: http://www.ijdb.ehu.es/web/contents.php?vol=50\&issue=2-3

See our Special Issue Developmental Genetics of Drosophila edited by Alain Ghysen at: http://www.ijdb.ehu.es/web/contents.php?vol=42\&issue=3

Cell proliferation during the early compartmentalization of the Xenopus laevis inner ear Quincy A. Quick and Elba E. Serrano

Int. J. Dev. Biol. (2007) 51: 201-210

The role of homeotic genes in determining the segmental pattern of chordotonal organs in Drosophila. Darren C C Wong and David J Merritt

Int. J. Dev. Biol. (2002) 46: 475-481 